\title{
Challenge in Learning English: Understanding Student Resilience
}

\author{
Ita Permatasari ${ }^{1}$, Titik Rahayu ${ }^{2}$, Imam Mudofir ${ }^{3}$, Muhyiddin Aziz $^{4}$, Eda Maaliah ${ }^{5}$ \\ State Polytechnic of Madiun, Jl. Serayu No.84, Madiun City ${ }^{1,2,3,4,5}$ \\ \{permatasari.ita@pnm.ac.id ${ }^{1}$ \}
}

\begin{abstract}
Resilience is the way how an individual deal with obstacles or problems. Some factors influence each student's resilience, outside and inside of each individual, called as risk and protective factors. This research was aimed to identify the risk and protective factors that affect the student's resilience. Moreover, the objective was also to find out how those factors affected the student's resilience. The scope of the research was the student of English Department in the first year that got GPA lowers than 3.00. This case study collected the data by exploring the academic score, conducting biographical research by interviewing the student and the lecturers, and analyzing interviewsessions-diaries of the student. The findings showed that the risk factor affecting the student's resilience came from the environment, in which the family was less supportive and low expectation. Furthermore, the protective factors which affecting the student's resilience are low family stress and good child relationship. Dealing with how those factors affecting the student's resilience, it was found that the less supportive aspect made the student did not bond with parents that caused low surveillance for the student's achievement. Besides, the low expectation from the family established low resilience.
\end{abstract}

Keywords: Resilience, Risk Factors, Protective Factors

\section{Introduction}

As the members of the parts of the university, freshmen are tended to adapt with all of aspects in college life. This condition is the transformation from Senior High School to higher education. The students will face new condition of learning teaching atmosphere, curriculum and administration. Besides, they will meet new friends and lecturers which affect their social life during their time in the campus. A previous study by Pickard [1] mentioned about how the transformation of the latest level of education to the next level of education brings an individual to experience a certain obstacles as the mean of adaptation to multiple variables. Therefore, the students need to deal with those conditions well in order to be success in the college life.

Being English Department students in the first year is also a new thing to deal with as almost all of the classes or materials are delivered using English. It becomes one of obstacles that they should face. In Indonesia, English is not the first language that commonly mastered by the students. It usually becomes the second or the third language that they mastered. 
However, those obstacles as mention above can be handled if the students have good resilience. Calhoun et.al [2] argued that resilience in academic sector includes some actions of reworking or adaptation that can be categorized as complex process.

Resilience is the way how an individual deal with obstacles or problems. It can turn into a positive way or vice versa depends on the individual itself. Some factors influence each student's resilience, outside and inside of each individual. Related to resilience, two factors cannot be separated from it, called as risk and protective factors in which influenced by someone's habit or action that can evolve and acquire [3].

The first factor that influences the resilience of each individual is risk factors. Risk factors can be defined as quantifiable attribute of certain group of people included their circumstances which affect certain individual in negative way [3]. It can be said that risk factors bring disadvantages to the individual, in this term is the student. These risk factors will affect the students' achievements in the class, or the process of learning that they follow in the class.

The second factor is protective factors. Protective factor is related to the way a certain individual face such problems, obstacles or negative situation with her or his personality in which this can bring a positive or good outcomes without affecting in negative way. In other words, it can be said that protective factors is a common difficulty in doing adaptation to a certain situation [4]. A previous study [3] shows that a person or individual can combine disturbance or confusion with resiliency by having protective factors.

This research focused on what risk factor and protective factor that affect the students' resilience, in this case, those students who have GPA lower than 3. Moreover, it analysed deeper into how those factors affect the students. Based on the background of this research, the researcher proposes a research entitled "Challenge in Learning English: Understanding Student Resilience".

\section{Literature Review}

\subsection{Resilience}

Resilience is related to adaptation of the students in facing challenges in certain environment. It can be defined as victorious way of adapting with problematic or stressful situations around that individual such as penury, problematic family, harsh environment, and bullying [5]. Moreover, resilience also can be described as how the individual capable to deal with the problems that occurs, for example when the student get difficulties with the the second language used in the classroom and he or she could overcome it [3].

The term resilience is also can be considered to be a process and an ability of certain individual to react or recover from traumatic events. Another definition of resilience comes from Calhoun [2] that academic resilience related to how the students face all of the obstacles or problem during the teaching learning process or any activity that happens in the school.

Resilience is related to the capability of certain individual when he or she has to deal with obstacles or problems arisen in the pace of life [6]. When someone having resilience, it means that the adaptation capability of that person is quite good, can be seen by the flexibility in response and how the process of adaptation out coming the positive way [7]. In a nutshell, resilience can be understood as an ability or process of a student to overcome or face the challenges or problems in order to deal with or adapt positively to them. 


\subsection{Factors Related to Resilience}

There are some factors related to resilience [8], namely:

a) Focusing on objective

b) Having strong personal motive

c) Around supportive family

d) Experiencing good academic environment

Other factors that are related to resilience are mentioned as follows [3]:

a) Constructive sentiment

b) Capability to overcame obstacles

c) Could developing good self-perception

d) Implementing intellectual affability

e) Studied cooperation

f) Having capability in dealing with stress

g) Connected or having good interactions with environment

It can be said that resilience are affected of some factors as mention above. Students' resilience depends on inside factors and outside factors. Those factors can strengthen or weaken the resilience, namely risk factors and protective factors.

\subsection{Risk and Protective Factors}

The first factor that influences the resilience of each individual is risk factors. Wright and Masten [4] argued in the term of risk factors which has definition as a certain situations of a group of people or environment which influenced the individuals in that group to have negative way of deal. It can be said that protective factors related to the personality or the capability of the people to deal with negative aspects which occur around her/him. As those people have a strong behaviours or good characteristic of adaptation, even when the risk factors hit them, they can deal it in positive way. Based on the previous research [3], as long as an individual at least has two protective factors, it can be from that individual itself or from the environment; it will make the development of resiliency even when some factors may interference the resilience.

\subsection{Factors to Build Students' Resilience}

There are some factors that may help the academic resilience increase or develop [5], such as:

a) Affinity of the students and the teachers

b) Atmosphere of the school environment

c) Capability of the student, and

d) The instructions that are used by the teacher

The situation in the academic environment can help the students to improve or develop their capability to become resilience, indeed with the help of the teachers. It can be done by encouraging the students to do their best as they have responsibility to reach their success. Moreover, by the teachers give a clear expectation, it will help the students to reach that situation. Furthermore, creating good academic environment and giving good positive interactions will have the students build their resiliency. 


\section{Methodology}

In order to answer the two research problems, the researcher used qualitative design. This research is categorizing as case study in which the researcher conducting in depth research with an individual or group of individuals. Case study is a type of study, in which the researcher focuses on one phenomenon happens in certain situation, and it is aimed to see that phenomenon clearly and deep [9]. Moreover, another definition comes from Cresswell [10], that case study focuses on one case that happen in certain situation and this case is related to certain system happens in that setting. Bounded system is related to a context that is attach to specific circumstances.

The subject of the research was a freshman of the second semester of English Department. This student become the only student in her year who got GPA lower than 3,00. Moreover, the researchers conducted interview with the lecturers who taught her in the first semester. In order to protect the subject of this study, all the mentioned name had been changed. There are interview-sessions-diaries analysis, academic record, interview and biographical research as the source of the data. The personal journal was submitted to the researcher every week.

For collecting the data, the researcher got the data by seeing the student's academic record and conducting biographical research. The biographical research was done by interviewing the student and the lecturers. Furthermore, every week the student wrote interview-sessionsdiaries which consist of reflective story for a week consist of problems or obstacles that she faced in a week.

In analysing the result of the diary written in each week, the researcher did interviewssessions-diaries analysis. Then, the researcher analysed all of the data gathered after doing several interviews and analysing the diaries by using content analysis. In this study, the data were analysed by folloing some steps namely coding the data, reducing the data, displaying the data and make inference of that data [9].

\section{Result and Discussion}

In order to protect the student's privacy, the participant of the research is called as Resilia. She is one of the students of English Department in the first year. There are 3 classes in this year and she was one of the students in class B. There are 86 students in this year and she is the only student who got GPA lower than 3,00. The researchers found it as an "anomaly" seeing the other students at least could pass 3,00 .

For collecting the data, the first data that was analysed is the result of academic record. Resilia is still in the first year, the result of the first semester was analysed. There are some aspects that were taken under consideration. First aspect is her GPA. Seeing from the academic record, Resilia could not pass GPA with the score 3,00. Compare to her friends in her year, she is the only student who could not pass 3,00 . The second aspect is her score in each subject. There were 10 subjects that she had to pass in the first semester. During this first semester, she had 35 hours meeting for a week; consist of practical subjects and theoretical subjects. The subjects in this semester are mostly basic subjects such as Basic Speaking, Basic Listening, and Basic Reading etc. In some subjects she got score which categorized as C. There is no subject in which she got A.

In order to find the risk factors that Resila faced, there were interviews conducted. The interviews were carried out twice, with Resilia and also some lecturers which had already taught her. The interview with Resilia was developed by considering some indicators such as 
"poverty, family dysfunction, family conflict, lower economic status, lack of social support, marital conflict and domestic violence, parent is less supportive, affectionate and playful, lack of positive parenting skills. There was semi-structured interview conducted to explore the risk factors" [3].

Based on the result of interviews, it was found that she came from middle class family. Her father is a merchant and her mother helps with the business. She lives with her parents with 10 year-old brother and enrolled the university without scholarship. Her parents paid her full tuition.

Table 1. Result of Environmental Risk Factors

\begin{tabular}{ll}
\hline Environmental Risk Factors & Occurs \\
\hline Poverty & \\
Family dysfunction & \\
Family conflict & \\
Lower economic status & \\
Lack of social support & \\
Marital conflict and domestic violence & \\
Harsh discipline & $\mathrm{V}$ \\
Parent is less supportive, affectionate and playful & $\mathrm{V}$ \\
Lack of positive parenting skills & \\
\hline
\end{tabular}

Resilia described her family just like the "just so so" family. Her father background of the study is Junior High School, while her mother completed her study to Senior High School. Her parents enacted tough discipline system in the house. There was schedule that she and her brother had to follow. Sometimes, if she or her brother could not follow the rule, they would get punishment like cleaning certain area of the house or omitting her pocket money. Dealing with conflict, there were just small arguments that happen in her family.

The second risk factors that occur is, her parent is less supportive, affectionate and playfull. Her parents spent quite time outside the house to take care of the business. They did not spend enough time to eat or watch TV together or even to ask about the progress that she had made. She did not share the problems or obstacles that she faced in the campus with her parents. They did not ask about her score, her subjects or her friends in the class.

From those explanation, it can be said that two risk factors affect Resilia's resilience. Those risk factors are harsh discipline and less supportive and affecionate action from her parents. The result reveals that Resilia came from a family with high expectation. As her parents' background of the study were not to higher education or college, they demanded the children to get higher education. The table below shows the environmental protective factors that affect her resilience.

Table 2. Environmental Protective Factors

\begin{tabular}{ll}
\hline Environmental protective factors & Occurs \\
\hline Low family stress & \\
Child relationship & \\
Parenting skills & \\
Child attachment & \\
Role models & $\mathrm{V}$ \\
High expectations & \\
Family support & \\
Family guidance & \\
Opportunities for meaningful family involvement & \\
Respectful communication & \\
\hline
\end{tabular}


Eventhough she did no share her college life with her parents, her parents attempted to give all the facilities needed for her her study. She got laptop and smartphone to support her activity during her learning process. The tuition was also paid ontime by her parents. If she had to copy her module or print her assignmet, her parents give her money to deal with that. They always remind her to be serius in her study and get better education than them.

Discussing about the academic resilience which come from individual factors, table 3 shows the result of protective factors that Resilia has and does not have. The result reveals that she was not optimism in cetain situation, she had self-respect to herself, she was categorized as persistence, when she got problem she try to solve it by herself. Furthermore, she was categorized as student wh has critical thinking and locus of control. Dealinng with protective factors, she had direction or mission, motivation and sense of purpose. The result reveals tha she had low optimism especially after she got a bad result of the test. Sometimes she asked herself whether she could do it or not. As most of the materials in English Department were delivered using English, it made her to work harder.

Table 3. Individual Factors

\begin{tabular}{|c|c|}
\hline Academic Resilience & Occurs \\
\hline Individual Factors & \\
\hline Optimism & \\
\hline Empathy & \\
\hline Self-steem & \\
\hline Direction or mission & $\mathrm{V}$ \\
\hline Determination & \\
\hline Perseverance & \\
\hline Motivation & $\mathrm{V}$ \\
\hline Problem Solving Skills & \\
\hline Crtitical Thinking & \\
\hline Autonomy & $\mathrm{V}$ \\
\hline Internal locus of control & \\
\hline Sense of purpose & $\mathrm{V}$ \\
\hline
\end{tabular}

She has individual direction or mission. She set the target that she should achive as her parents asked high expectation to her. However, she mentioned that actually she did not set the target way too high as she was not sure whether she could reach the goal. For the motivation, sometimes she got it from seeing her classmates' achievements. She believed that if her friends can reach that point, it means that she has that capability too. Unfortunatelly, she got the motivation usually after she get down. It take such a time to make her realized that she can do better next time.

Dealing with autonomy, the result showed that Resilia could work individually. At first, she tried to finish the tasks by herself, and if she found difficulties, she would asked her friends. She said she never reached the lecturers personally to ask about the assignments or difficulties that she faced during learning process. The last factors is sense of purpose. It was discoverd that she actually set an objective. It can be seen from the result of interview-diariessessions in which she tried to write down her target during a week for example. Eventhough sometimes she could not reach the purpose, she always set the purpose.

Risk and protective factors is factors that cannot be seperated when we are discussing about resilience. The question comes up on how these factors affect student's achievement. In previous sub-chapter, we have already discussed about the risk and protective factors that Resilia has. The result will be presented in the following table. 
The result of the interview with the lecturers who taught Resilia in the first semester said that she was not an active student in the class. She fulfilled the 16 meetings, but during the learning process, she did not ask or give her opinion if the lecturer gives her chances. Moreover, seeing from the academic record and the result of the interviews, she tends to get lower score in productive skills subject, like speaking and writing. Besides, she got low score in Basic Grammar and Listening subject. Her performance was not to got during those subjects. Some lecturers rated her performance as" below averaged".

In terms of the family environment, there are two risk factors that affect Resilia resilience. Those two aspects are harsh discipline in her family and her parents is less supportive and affecionate. These factors affected in how she experienced stressed with the discipline system that her family has. Moreover, they way her parents showed less supportive action with her study may affect her resilience. Sharing about her study, the problem and obstacle that she faced were not happen in her family.

As a result of the findings, this case demonstrates a non-academically resilient student because of the lack of environmental protective factors such as low family stress, child relationship, parenting skills, child attachment, family support, family guidance and opportunities for meaningful family involvement.

From the findings of this study, it can be said that it supports the literature that was presented in this study. Some factors, including risk and protective factors had taken a certain influence to the student's resilience. Some factors came from the student, in which it came from the internal factor, and some factors came from the environment. The environmet influenced the student including the family factors and academic situation. It is in line with the previous study [11], two factors that influenced the students came from inside and outside of the student. The way the individual deals with obstacles and the quality that the individual has affect the resilience. Besides, the family and the academic situation also took a part in the resiliency.

In Resilia's case, it turned out that the family factors or parenting skill that she experienced were influenced her negative academic outcomes. It can be said that she experienced less protective factors which cause negative outcome. In this case, having low GPA or, could not pass 3,00 for the GPA score. This result of the study is in line with Masten and Reed [8], in which the way how parenting skill applied to the student will influenced the development of resilience. It will affect the student's discipline control, self esteem and others positive adjusment that can be developed.

\section{Conclusions}

Based on the result of the research, it can be concluded that: The risk factors that the student experienced comes from her environment. The harsh discipline in the house derived a stress to her. Besides, family environment shows less supportive, affection and playful. This condition leads the students to face the problems and obstacles during the study. Those risk and protective factors affect the students' achievement. It can be said that the risk factors that occurs lead her to get low achievement. In this case, the student rated as low average student seeing the result of GPA. 


\section{Acknowledgements}

Foremost, we would like to express our sincere gratitude to State Polytechnic of Madiun for the support to finish this study. Our sincere thanks also go to all of the lecturers in English Department for the continual support.

\section{References}

[1] Pickard, L., McKenna, J., Brunton, J. A., \& Utley, A., “ Personal development, resilience theory and transition to university for 1st year students", 293-302,2017, https://doi.org/10.4995/head17.2017.5172.

[2] Calhoun, Y., Snodgrass Rangel, V., \& Coulson, H. L. , "Educational Resilience at Risk? The Challenges of Attending an Early College High Schoo",. Urban Review, 51(2), 301-325, 2017, https://doi.org/10.1007/s11256-018-0481-X.

[3] Rojas F., L. F., "Factors Affecting Academic Resilience in Middle School Students: A Case Study" , GiST Education and Learning Research Journal, 11(11), 63-78, 2015, https://doi.org/10.26817/16925777.286.

[4] Wright, M. O. D., \& Masten, A. S, "Resilience processes in development", In S. Goldstein, \& R. B. Brooks (Eds.), Handbook of resilience in children (pp 17-25). New York: Springer, 2005.

[5] Cefai, C., Matsopoulos, A., Bartolo, P., Galea, K., Gavogiannaki, M., Zanetti, M. A., ... Lebre, P. "A resilience curriculum for early years and primary schools in Europe: Enhancing quality education”, Croatian Journal of Education, 16(SPEC. EDITION 2), 11-32, 2014.

[6] Gonçalves, A. M., Cabral, L. do R., Ferreira, M. da C., Martins, M. da C., \& Duarte, J. C., "Negative Life Events and Resilience in Higher Education Students", The European Journal of Social and Behavioural Sciences, 19(2), 2381-2392, 2017 https://doi.org/10.15405/ejsbs.211.

[7] Anasuri, S., Ph, D., \& Anthony, K., "Resilience levels among college students : A comparative study from two southern states in the USA", IOSR Journal of Humanities and Social Science, 23(1), 52-73, 2018, https://doi.org/10.9790/0837-2301035273.

[8] Masten, A. S., \& Reed, M. J, "Resilience in development", In C. R. Snyder \& S. J. López (Eds.), Handbook of positive psychology (pp. 74-88), New York: Oxford University Press, 2002.

[9] Ary, D. et al, Introduction to Research in Education. Eighth Edition, Belmont: Wadsworth Group, 2010.

[10] Cresswell, John W., Educational Research: Planning, Conducting, and Evaluating Quantitative and Qualitative Research(4th ed,. Boston: Pearson Education Inc, 2012.

[11] Schoon, I, Risk and resilience: adaptations in changing times, New York:Cambridge University Press, 2006. 